\title{
Neurosurgical Site Infection Prevention: Single Institute Experience
}

\author{
Xue JIANG ${ }^{1}$, Jianjun $\mathrm{MA}^{2}$, Fang $\mathrm{HOU}^{1}$, Juan $\mathrm{LI}^{1}$, Ruigang $\mathrm{LI}^{1}$, Hongjuan LANG ${ }^{3}$ \\ ${ }^{1}$ Tangdu Hospital , The Fourth Military Medical University, Department of Neurosurgery, Xi'an, China \\ ${ }^{2}$ Tangdu Hospital , The Fourth Military Medical University, Department of Urology, Xi'an, China \\ ${ }^{3}$ Tangdu Hospital , The Fourth Military Medical University, Department of Nursing, Xi'an, China
}

\section{ABSTRACT}

AIM: To estimate the effect of a multimodal prevention program on controlling surgical site infection (SSI) risk among neurosurgical patients.

MATERIAL and METHODS: This prospective study was conducted among adult patients who have undergone neurosurgical procedures in a tertiary-care university-affiliated hospital during January 2008 to December 2013 since the implementation of an infection control program. SSI cases among inpatients were identified by daily active searches, whereas post-discharge surveillance was performed for outpatients through telephone contact 30-35 days after surgery, according to the definition proposed by the Center for Disease Control. The variation of SSI rate during the study period was analyzed by Cochran-Armitage trend test.

RESULTS: Overall, a total of 3042 patients were enrolled and $112 \mathrm{SSI}$ cases were identified during the studied period. SSI more likely occurred in patients with older age $(t=5.16, p<0.01)$, undergoing emergency operations $\left(x^{2}=50.5, p<0.01\right)$, having higher American Society of Anesthesiologists (ASA) scores $\left(x^{2}=7.2, p=0.01\right)$ and clean contaminated wound or above $\left(x^{2}=53.8, p<0.01\right)$. The annual incidence rate of SSI was $6.21 \%, 5.01 \%, 3.89 \%, 3.06 \%, 2.38 \%$ and $2.28 \%$, respectively, showing a significant decreasing trend $(z=3.96, p<0.01)$.

CONCLUSION: The results provide evidence of a significant decreasing trend in the SSI rate following the infection prevention program, demonstrating the role of multimodal approach in controlling SSI.

KEYWORDS: Surgical site infection, Neurosurgery, Surveillance, Annual incidence rate, Multimodal approach, Cochran-Armitage trend test

\section{INTRODUCTION}

Surgical site infections (SSIs) are the most commonly encountered healthcare-associated infections among surgically treated patients (18). The reported incidence of SSls varies widely, ranging from $1 \%$ to $17 \%$, depending on the definitions used for infection, length of postoperative follow-up, reporting institution, and the type of surgical procedure $(13,15,29$, $30)$. Despite the marked improvement in surgical practice and infection control techniques, SSIs remain a worrisome burden of hazard for both patients and healthcare services in terms of morbidity, mortality and cost $(1,3,21)$, posing a major threat to the well-being of post-surgical patients.

Although complete eradication of SSls seems impossible to achieve, most of them are potentially preventable though effective prevention strategies (7). Scrupulous surveillance, as growing studies indicated (5), can lead to a substantial reduction in the incidence of SSIs. Haley et al. (9) reported that hospitals with a robust surveillance and control program were able to lower their SSI rates by $19-41 \%$ over the course of 6 years. Based on data from Dutch surveillance system, 
Geubbels et al. observed that the risk of infection was reduced for patients who had an operation during the fourth surveillance year and decreased further for patients undergone surgery during the fifth surveillance year (6). Surveillance has thus been widely accepted as the primary step towards effective prevention of SSIs (9).

The occurrences of SSIs are determined by multiple exogenous and endogenous factors and influenced by the characteristics of the patient, operation, personnel, and hospital (10). Therefore, one of the key components to any SSI prevention strategy should involve a multi-disciplinary approach and all relevant individuals should be committed equally to the process improvement as a team. Keeping the learnt lessons in mind, we conducted a multimodal SSI prevention program in a tertiary-care university-affiliated hospital over a 6-year period since 2008. In the present study, we aimed to determine whether the trend of SSI incidence did change or not following the implementation of the program.

\section{MATERIAL and METHODS}

\section{Recruitment}

This prospective study was conducted at the Neurosurgical Department of Tangdu Hospital, a hospital affiliated to the Fourth Military Medical University in Xi'an city of Shanxi province of China. Patients, admitted for cranial surgery between January 2008 and December 2013 were eligible for recruitment if they were aged more than 18 years, free from any intracranial infections at the time of their surgery and accompanied by relatives/friends who provided informed consent in favor of recruitment for the study. Patients who underwent diagnostic procedures only or endoscopic surgery, along with those who died within 48 hours from the time of surgery, were excluded. The study protocol was approved by the Institutional Ethics Committee of the Fourth Military Medical University.

\section{Data Collection}

SSls were identified during postsurgical hospital stay or within 30 days following operation by post-discharge survey according to definition by the Centers for Disease Control and Prevention and National Healthcare Safety Network (CDC/NHSN) (11). According to the criteria, SSls were classified as: superficial, deep or organ/space infections. Surgical wound contamination potential was categorized as: clean, potentially contaminated or contaminated. In addition, patients' preoperative clinical conditions were assessed using the criterion proposed by the American Society of Anesthesiologists (ASA) score. The surgical wound was classified as: I (Clean), II (Clean-Contaminated), III (Contaminated) and IV (Dirty-Infected).

Two nurses, who were specifically trained for the surveillance on surgical site infections, were responsible for data collection. They were directly supervised by the principal investigator. Data concerning demographic information, potential risk factors and surgical indications were noted from medical records. Regarding information about SSI, parameters including the interval between date of surgery, SSI report and place of diagnosis (during hospitalization or after discharge) were obtained.

During hospitalization, the two designated nurses performed daily active surveillance for SSIs among the recruited patients. The diagnoses were finally confirmed by the attending neurosurgeon. Post-discharge surveillance was performed through telephone interviews $30-35$ days after surgery. The patients were asked to describe the incision site in details, including whether there were any signs of temperature, redness, dehiscence and pus collection in the surgical wound along with any secretion thereof, if present, its color, location and quantity. Each case was then assessed by attending surgeons and if necessary, by the team of assistants. Cases highly suspected to be suffering from SSIs, were then asked to return to hospital for further examination and treatment.

\section{SSI Prevention Program}

A multidisciplinary team, comprised of senior medical personnel and nursing staff, department administrators and one epidemiologist, was set up in 2008, in the said department, taking the responsibility for providing review and guidance for the program operations, strategies and plan for SSI prevention. A campaign has been promoted by the team to ensure proper implementation of a series of measures. For all the attending surgeons and nursing staff, getting involved in this campaign and abiding by the supervision system, were mandatory.

Initially, the medical and nursing staffs were provided with a multi-component educational training focusing on risk identification, assessment and management strategies, through regular seminars, workshops, dissemination of guidelines, posters and leaflets. Additionally, patients and caregivers were also informed about SSI prevention strategies through printed materials and verbal discussions. The method of assessment of SSls were standardized and reinforced. The attending medical surgeons and nurses were required to review all healthcare procedures involving these cases and possible risk factors were identified through discussion and evaluation.

Workshops and symposiums followed next to ensure adequate implementation of prevention strategies including proper hand-washing, judicious administration of appropriate antibiotics, aseptic draping and dressing including hair removal and proper skin preparation of the operative site.

\section{Statistical Analysis}

Statistical analyses were performed using the Statistical Analysis System (SAS) (version 8.2). Variables were described by frequencies for categorical variable and mean \pm standard deviation (SD) for continuous variables. The variations of SSI rate and SSI-associated risk factors over the follow-up years were analyzed using Cochran-Armitage trend test. Comparison of variables between SSI positive group and negative group was conducted using $x^{2}$ test for categorical variables and student-t test was used for continuous variables. A $P$-value $\leq 0.05$ was considered statistically significant. 


\section{RESULTS}

Over a period of 6 years from January 2008 to December 2013, a total of 3042 patients fulfilled the inclusion criteria and were enrolled into the study. The mean age of the patients was 48.4 years and $58.0 \%$ of all cases were male. Among patients, $38.0 \%$ underwent emergency operations and $62.0 \%$ had elective surgeries. $38.2 \%$ were classified as ASA1 while $61.8 \%$ were ASA2 or above. The detailed distribution of the other socio-demographic and surgical factors among the patients across the years (2008-13) was presented in Table I. The distribution of mean age, gender, use of surgical drain, wound type and ASA score did not change significantly over years during the study period. However, the proportion of patients having undergone emergency operations $(\mathrm{z}=4.37$, $p<0.01)$ consistently increased over time.

During 2008-2013, the follow-up rates for post-discharge patients were $90.3 \%, 94.2 \%, 96.8 \%, 95.7 \%, 92.3 \%$ and $94.5 \%$, respectively. The overall follow-up rate was $94.1 \%$. Among 3042 patients, 112 suffered from SSIs, resulting in a mean incidence rate of $3.68 \%$. Within these 112 cases, 36 (32.1\%) were diagnosed during post-operative hospital stay while $76(67.9 \%)$ were identified after discharge. SSIs were more likely to affect patients with older age $(t=5.16, p<0.01)$, emergency operations $\left(x^{2}=50.5, p<0.01\right)$, higher ASA scores $\left(x^{2}=7.2, p=0.01\right)$ and clean contaminated wound or above $\left(x^{2}=53.8, p<0.01\right)$. However, no gender difference was observed among patients with or without SSIs (Table II).
The annual SSI rates are presented in Table III. The highest rate was observed in 2008 (6.21\%), followed by 2009(5.01\%), 2010(3.89\%), 2011(3.06\%), 2012(2.38\%) and the lowest rate was in $2013(2.28 \%)$. The annual rate consistently decreased during the whole studied period $(z=3.96, p<0.01)$.

\section{DISCUSSION}

Despite the improvement in medical techniques and advances in infection control practices, SSI remains a substantial cause for mortality and morbidity among postoperative patients. In the present study, we analyzed the annual incidence of SSI during 2008 to 2013 in the Neurosurgery Department of Tangdu Hospital in Xi'an city of Shanxi province of China, using prospectively collected data through comprehensive active surveillance. We observed a clear downward trend in the annual incidence rate of SSI (from $6.21 \%$ in 2008 to $2.28 \%$ in 2013) during the study period resulting from the SSI prevention program. To our knowledge, this is the first prospectively studied evaluation of an SSI prevention program in China.

Based on the prior observations, the reported SSI incidence rate among neurosurgical patients had ranged from $1.25 \%$ to $17 \%$ without prophylactic antibiotics and $0.3 \%$ to $3.0 \%$ with prophylactic antibiotics $(3,12,15,17,28)$. An acceptable range of annual incidence rate of SSIs, as Haines suggested, should be less than $5 \%$ (8). In the current study, the proportion in the first two years during the studied period were slightly higher

Table I: Distribution of Socio-Demographic and Surgical Characteristics of Post-Surgical Patients Enrolled in the Study (2008-13)

\begin{tabular}{|c|c|c|c|c|c|c|c|c|}
\hline Factors & Total & $\begin{array}{c}2008 \\
(n=435)\end{array}$ & $\begin{array}{c}2009 \\
(n=478)\end{array}$ & $\begin{array}{c}2010 \\
(n=489)\end{array}$ & $\begin{array}{c}2011 \\
(n=523)\end{array}$ & $\begin{array}{c}2012 \\
(n=546)\end{array}$ & $\begin{array}{c}2013 \\
(n=571)\end{array}$ & $\mathbf{p}$ \\
\hline Age (yrs, Mean+SD) & $48.4 \pm 6.5$ & $47.3 \pm 7.1$ & $48.9 \pm 8.2$ & $48.3 \pm 7.4$ & $49.2 \pm 8.5$ & $48.6 \pm 9.1$ & $47.9 \pm 8.4$ & 0.76 \\
\hline Gender & & & & & & & & 0.59 \\
\hline Female & $1278(42.0)$ & $191(43.9)$ & $195(40.8)$ & $215(44.0)$ & 207 (39.6) & $233(42.7)$ & $237(41.5)$ & \\
\hline Male & $1764(58.0)$ & $244(56.1)$ & $283(59.2)$ & $274(56.0)$ & $316(60.4)$ & $313(57.3)$ & $334(58.5)$ & \\
\hline Type of surgery & & & & & & & & $<0.01$ \\
\hline Elective & $1885(62.0)$ & $300(69.0)$ & $304(63.6)$ & $314(64.2)$ & $324(62.0)$ & $321(58.8)$ & $322(56.4)$ & \\
\hline Emergency & 1157 (38.0) & $135(31.0)$ & $174(36.4)$ & $175(35.8)$ & $199(38.0)$ & $225(41.2)$ & $249(43.6)$ & \\
\hline ASA classification & & & & & & & & 0.69 \\
\hline ASA1 & $1163(38.2)$ & $170(39.1)$ & $183(38.3)$ & $177(36.2)$ & 195 (37.3) & $211(38.6)$ & $227(39.8)$ & \\
\hline Grouped ASA $(2,3)$ & $1879(61.8)$ & $265(61.9)$ & $295(61.7)$ & $312(63.8)$ & $328(62.7)$ & $335(61.4)$ & $344(60.2)$ & \\
\hline Type of Wound & & & & & & & & 0.95 \\
\hline Clean & 2644 (86.9) & $373(85.7)$ & $415(86.8)$ & $440(90.0)$ & $438(83.7)$ & $492(90.1)$ & $486(85.1)$ & \\
\hline Others (I, II, III, IV) & $398(13.1)$ & $62(14.3)$ & $63(13.2)$ & $49(10.0)$ & $85(16.3)$ & $54(9.9)$ & $85(14.9)$ & \\
\hline Drain Use & & & & & & & & 0.07 \\
\hline Yes & $542(17.8)$ & $68(15.6)$ & 78 (16.3) & $86(17.6)$ & $98(18.8)$ & $102(18.7)$ & $110(19.3)$ & \\
\hline No & $2500(82.2)$ & $367(84.4)$ & $400(83.7)$ & $403(83.4)$ & 425 (81.2) & 444 (81.3) & $461(80.7)$ & \\
\hline
\end{tabular}


Table II: Comparative Distribution of Socio-Demographic and Surgical Factors Across Post-Surgical Patients with or without SSI (200813)

\begin{tabular}{|c|c|c|c|}
\hline \multirow{2}{*}{ Factors } & \multicolumn{2}{|c|}{ SSI } & \multirow{2}{*}{$\mathbf{p}$} \\
\hline & Yes $(n=112)$ & No $(n=2930)$ & \\
\hline Age (yrs, mean+SD) & $53.3 \pm 8.9$ & $49.5 \pm 7.6$ & $<0.01$ \\
\hline \multicolumn{4}{|l|}{ Gender } \\
\hline Female & $46(41.1)$ & $1232(42.0)$ & 0.83 \\
\hline Male & $66(58.9)$ & $1698(58.0)$ & \\
\hline \multicolumn{4}{|l|}{ Type of surgery } \\
\hline Elective & $34(30.4)$ & $1851(63.2)$ & $<0.01$ \\
\hline Emergency & $78(79.6)$ & 1079 (36.8) & \\
\hline \multicolumn{4}{|l|}{ ASA classification } \\
\hline ASA1 & $29(25.9)$ & $1127(38.5)$ & 0.01 \\
\hline Grouped ASA $(2,3)$ & $83(74.1)$ & 1803 (61.5) & \\
\hline \multicolumn{4}{|l|}{ Type of Wound } \\
\hline Clean & $74(66.1)$ & 2606 (88.9) & $<0.01$ \\
\hline Others (I, II, III, IV) & 38 (33.9) & $324(11.1)$ & \\
\hline \multicolumn{4}{|l|}{ Drain use } \\
\hline Yes & $25(24.1)$ & $515(17.6)$ & 0.20 \\
\hline No & 87 (75.9) & $2415(82.4)$ & \\
\hline
\end{tabular}

Table III: Consistently Decreasing Incidence Rates of Surgical Site Infections Across Years (2008-13)

\begin{tabular}{cccr}
\hline Year & No. of patients & No. of SSI cases & SSI incidence rate (\%) \\
\hline 2008 & 435 & 27 & 6.21 \\
\hline 2009 & 478 & 24 & 5.01 \\
\hline 2010 & 489 & 19 & 3.89 \\
\hline 2011 & 523 & 16 & 3.06 \\
\hline 2012 & 546 & 13 & 2.38 \\
\hline 2013 & 571 & 13 & 2.28 \\
\hline Total & 3042 & 112 & 3.68 \\
\hline
\end{tabular}

${ }^{*} z=3.96, p<0.01$.

than $5 \%$, however, they were within the acceptable range in the following years and far lower than the most previous reports. The overall SSI incidence rate in 3042 eligible patients was $3.68 \%$, which was also within the acceptable range. This suggested that, although not all SSIs were preventable, feasible measures could substantially reduce the risk of SSIs.

Surveillance of SSIs has been an effective component of strategies to reduce the SSI risk. Feedback of SSI data to practicing surgeons has been shown, in multiple studies, to be associated with substantial reduction in the annual incidence of SSI $(4,5)$. In the National SSI surveillance in Italy, Marchi et al. observed that operations in hospitals with at least two years of surveillance showed a $29 \%$ lower risk of SSI (19). Similarly, Rioux et al. observed that the crude SSI incidence decreased from $3.8 \%$ to $1.7 \%$ after 6-year surveillance in hospitals in Northern France (25). In the present study, although the independent influence of the SSI surveillance and prevention program on observed decrease in SSI rates over time could not be demonstrated, we still could validly assume that, in light of previous studies, active surveillance is a strong approach to reduce SSI risk. 
Previous studies identified that a number of patient-related and surgical factors were associated with the increased risk of SSI $(3,14,16)$. Our data also did show that SSIs were more likely to occur in patients with older age, undergoing emergency operations, having higher ASA classification, clean contaminated wound or above, and with use of drain. Timely feedback to medical personnel, nursing staff, and caregivers regarding these factors and adverse health events, was helpful to enable them to take appropriate actions (2). To achieve this, we carried out a multimodal educational program. Measures like root cause analysis for severe infections, extensive education of medical and nursing staff on standardization of prevention practices and routine review of compliance rate were implemented. As a result, the SSI burden showed a significant decreasing trend, demonstrating the beneficial role of multimodal educational approaches in controlling SSI.

In any SSI prevention program, as studies indicated, the involvement and commitment of medical and nursing staff was not only desirable but also essential $(2,3)$. However, various factors might have substantial impacted on the adherence rate, including lack of awareness of available principles, absence of training, individual preferences and influence from colleagues. Failure to comply with the standard of care had frequently been reported $(20,23,27)$. In our program, all attending surgeons and nursing staff were mandatorily required to be involved in the SSI prevention campaign and abide by the supervision system. Continuous assessment and monitoring of compliance were conducted routinely since the implementation of the educational program. This could also have played a significant role in the reduction of SSI during the study period. Therefore, it seemed necessary to integrate compliance rate surveillance into the SSI prevention strategies.

There were some limitations in our study. First, we could not control for some potentially influencing factors while analyzing the trend of change in SSI incidence rate across years. This might have resulted in some residual confounding, since the distribution of factors like surgeries conducted in emergency, likely to be associated with increased SSI risk, showed a significant increasing trend over the studied years. This could potentially have resulted in underestimation of the decreasing trend of SSI as well as the effectiveness of the intervention program.

Second, in the present study, post-discharge surveillance was mainly based on telephone conversations, owing to its low resource-intensive nature and high compliance rate. However, this might have introduced some information bias as a few of the SSIs could be under-reported. To reduce this bias, the ideal methodology should, as studies pointed out, have a high follow-up rate, be cost-effective and have high sensitivity and specificity $(24,26)$. In our study, the follow-up was higher than $90 \%$ in each surveillance year, which was similar to that in previous studies. Meanwhile, the telephone interviews were conducted by trained professionals, who asked objective unambiguous questions. Hence we believe that the potential for information bias was low in our study.
Finally, detection and diagnosis of SSI in the current study were mainly based on self-reporting, hence detection/ reporting bias was inevitable. This could be one of the reasons why the observed burden of SSI was lower in our study than others. Some infections, like superficial SSI, might have gone unnoticed and thus under-reported. Direct observation of surgical sites by trained professionals, as proposed by Smyth et al., is the most accurate method to detect SSI (26). However, this was not possible, given the extensive requirement of human and financial resources. On the other hand, as suggested by Mitt et al. (22), some patients might have confused serous discharge with pus, resulting in overestimation. In the current study, patients having conditions highly suspected to be SSIs were asked to return to hospital for further examination and treatment. This approach might have minimized the aforementioned probability.

\section{CONCLUSION}

Based on our observations we could conclude that there was a significant decreasing trend in annual incidence rate of SSIs following a multimodal infection control program in the Neurosurgical Department of a tertiary care hospital in Xi'an, China. Continuous surveillance also seemed necessary for the development of evidence-based prevention principles and also as a powerful tool for SSI prevention. Simultaneously, mandatory training of medical and nursing staff should be encouraged to improve the surveillance system and the compliance rate.

\section{ACKNOWLEDGEMENTS}

This study is funded by Tangdu Hospital, the Fourth Military Medical University. The authors would like to express their sincere gratitude to the medical staff at the Department of Neurosurgery for their kind assistance in acquisition of data.

\section{REFERENCES}

1. Albers BA, Patka P, Haarman HJ, Kostense PJ: Cost effectiveness of preventive antibiotic administration for lowering risk of infection by $0.25 \%$. Unfallchirurg 97 : 625-628, 1994

2. Barchitta $M$, Matranga $D$, Quattrocchi $A$, Bellocchi $P$, Ruffino M, Basile G, Agodi A: Prevalence of surgical site infections before and after the implementation of a multimodal infection control programme. J Antimicrob Chemother 67:749-755, 2012

3. Buang SS, Haspani MS: Risk factors for neurosurgical site infections after a neurosurgical procedure: A prospective observational study at Hospital Kuala Lumpur. Med J Malaysia 67: 393-398, 2012

4. Gastmeier P, Geffers C, Brandt C, Zuschneid I, Sohr D, Schwab F, Behnke M, Daschner F, Ruden H: Effectiveness of a nationwide nosocomial infection surveillance system for reducing nosocomial infections. J Hosp Infect 64:16-22, 2006 
5. Gaynes RP, Culver DH, Horan TC, Edwards JR, Richards C, Tolson JS: Surgical site infection (SSI) rates in the United States, 1992-1998: The National Nosocomial Infections Surveillance System basic SSI risk index. Clin Infect Dis 33 Suppl 2: S69-77, 2001

6. Geubbels EL, Nagelkerke NJ, Mintjes-De Groot AJ, Vandenbroucke-Grauls CM, Grobbee DE, De Boer AS: Reduced risk of surgical site infections through surveillance in a network. Int J Qual Health Care 18: 127-133, 2006

7. Gibbons C, Bruce J, Carpenter J, Wilson AP, Wilson J, Pearson A, Lamping DL, Krukowski ZH, Reeves BC: Identification of risk factors by systematic review and development of riskadjusted models for surgical site infection. Health Technol Assess 15: 1-156, 2011

8. Haines SJ: Efficacy of antibiotic prophylaxis in clean neurosurgical operations. Neurosurgery 24: 401-405, 1989

9. Haley RW, Culver DH, White JW, Morgan WM, Emori TG, Munn VP, Hooton TM: The efficacy of infection surveillance and control programs in preventing nosocomial infections in US hospitals. Am J Epidemiol 121: 182-205, 1985

10. Healey MA, Shackford SR, Osler TM, Rogers FB, Burns E: Complications in surgical patients. Arch Surg 137: 611-617; discussion 617-618, 2002

11. Horan TC, Andrus M, Dudeck MA: CDC/NHSN surveillance definition of health care-associated infection and criteria for specific types of infections in the acute care setting. Am J Infect Control 36: 309-332, 2008

12. Hover AR, Sistrunk WW, Cavagnol RM, Scarrow A, Finley PJ, Kroencke AD, Walker JL: Effectiveness and cost of failure mode and effects analysis methodology to reduce neurosurgical site infections. Am J Med Qual 2013

13. Inigo JJ, Bermejo B, Oronoz B, Herrera J, Tarifa A, Perez F, Miranda C, Lera JM: Surgical site infection in general surgery: 5 -year analysis and assessment of the National Nosocomial Infection Surveillance (NNIS) index. Cir Esp 79: 224-230, 2006

14. Jain RK, Shukla R, Singh P, Kumar R: Epidemiology and risk factors for surgical site infections in patients requiring orthopedic surgery. Eur J Orthop Surg 25(2):251-254, 2015

15. Kasatpibal N, Norgaard M, Jamulitrat S: Improving surveillance system and surgical site infection rates through a network: $A$ pilot study from Thailand. Clin Epidemiol 1:67-74, 2009

16. Korinek AM, Golmard JL, Elcheick A, Bismuth R, van Effenterre $\mathrm{R}$, Coriat P, Puybasset L: Risk factors for neurosurgical site infections after craniotomy: A critical reappraisal of antibiotic prophylaxis on 4.578 patients. Br J Neurosurg 19:155-162, 2005

17. Kulkarni AV, Drake JM, Lamberti-Pasculli M: Cerebrospinal fluid shunt infection: A prospective study of risk factors. J Neurosurg 94: 195-201, 2001
18. Mangram AJ, Horan TC, Pearson ML, Silver LC, Jarvis WR: Guideline for Prevention of Surgical Site Infection, 1999. Centers for Disease Control and Prevention (CDC) Hospital Infection Control Practices Advisory Committee. Am J Infect Control 27: 97-132; quiz 133-134; discussion 196, 1999

19. Marchi M, Pan A, Gagliotti C, Morsillo F, Parenti M, Resi D, Moro M: The Italian national surgical site infection surveillance programme and its positive impact, 2009 to 2011. Euro Surveill 19: 2014

20. Meeks DW, Lally KP, Carrick MM, Lew DF, Thomas EJ, Doyle PD, Kao LS: Compliance with guidelines to prevent surgical site infections: As simple as 1-2-3? Am J Surg 201: 76-83, 2011

21. Merollini KM, Crawford RW, Whitehouse SL, Graves N: Surgical site infection prevention following total hip arthroplasty in Australia: A cost-effectiveness analysis. Am J Infect Control 41: 803-809, 2013

22. Mitt P, Lang K, Peri A, Maimets M: Surgical-site infections following cesarean section in an Estonian university hospital: Postdischarge surveillance and analysis of risk factors. Infect Control Hosp Epidemiol 26: 449-454, 2005

23. Nemeth TA, Beilman GJ, Hamlin CL, Chipman JG: Preoperative verification of timely antimicrobial prophylaxis does not improve compliance with guidelines. Surg Infect (Larchmt) 11: 387-391, 2010

24. Noy D, Creedy D: Postdischarge surveillance of surgical site infections: A multi-method approach to data collection. Am J Infect Control 30: 417-424, 2002

25. Rioux C, Grandbastien B, Astagneau P: Impact of a six-year control programme on surgical site infections in France: Results of the INCISO surveillance. J Hosp Infect 66: 217-223, 2007

26. Smyth ET, Emmerson AM: Surgical site infection surveillance. J Hosp Infect 45: 173-184, 2000

27. Tourmousoglou CE, Yiannakopoulou E, Kalapothaki V, Bramis J, St Papadopoulos J: Adherence to guidelines for antibiotic prophylaxis in general surgery: A critical appraisal. J Antimicrob Chemother 61: 214-218, 2008

28. Valentini LG, Casali C, Chatenoud L, Chiaffarino F, UbertiFoppa C, Broggi G: Surgical site infections after elective neurosurgery: A survey of 1747 patients. Neurosurgery 62: 88-95; discussion 95-86, 2008

29. Waits SA, Fritze D, Banerjee M, Zhang W, Kubus J, Englesbe MJ, Campbell DA Jr, Hendren S: Developing an argument for bundled interventions to reduce surgical site infection in colorectal surgery. Surgery 155: 602-606, 2014

30. Ward VP, Charlett A, Fagan J, Crawshaw SC: Enhanced surgical site infection surveillance following caesarean section: Experience of a multicentre collaborative post-discharge system. J Hosp Infect 70:166-173, 2008 